\title{
A NATUREZA DO SUPREMO TRIBUNAL FEDERAL À LUZ DA TEORIA KELSENIANA DE JURISDIÇÃO CONSTITUCIONAL: \\ A TENTATIVA DE CRIAÇÃO DE UM TRIBUNAL CONSTITUCIONAL BRASILEIRO
}

\author{
THE ROLE OF THE SUPREME FEDERAL COURT UNDER KELSEN'S THEORY OF \\ CONSTITUTIONAL JURISDICTION: AN ATTEMPTTO CREATE A BRAZILIAN \\ CONSTITUTIONAL COURT
}

\section{RESUMO}

A teoria kelseniana da jurisdição constitucional propõe a criação de um Tribunal Constitucional, destinado a garantir a supremacia da Constituição. No Brasil, até a Emenda Constitucional 16/65 o controle de constitucionalidade se dava apenas no modelo difuso, fruto do judicial review norte-americano. A partir de então, sistema brasileiro adotou um modelo misto de controle de constitucionalidade. Com a Constituição de 1988, ao STF foi lhe dada a função de zelar pela guarda da Constituição e promover o controle de constitucionalidade concentrado por meio do julgamento das Ações Diretas de Inconstitucionalidade genérica e por omissão, Ações Declaratórias de Constitucionalidade e das Arguições de Descumprimento de Preceito Fundamental. Feito esse breve histórico, o presente artigo se propõe a estudar a natureza do STF, de modo a analisar se sua função se correlaciona ao proposto por Hans Kelsen. Para tanto, a presente pesquisa utilizou-se do método indutivo, da pesquisa bibliográfica e análise doutrinária e legislativa.

Palavras-chave:Tribunal Constitucional. Controle de Constitucionalidade. Supremo Tribunal Federal.

\section{ABSTRACT}

Kelsen's theory of constitutional jurisdiction proposes the creation of a specialized body, a Constitutional Court. In Brazil, until Constitutional Amendment 16/65 constitutionality control was given only in the diffuse model, dueto the influence of judicial reviewin the USA legal system. Since then, the Brazilian system has adopted a mixed model of constitutionality control. The Constitution of 1988, states that the competence of the Supreme Federal Courtis primarily to safe guard the Constitution. Among the constitutional competences of the Supreme Federal Court, is to judge the direct action of unconstitutionality; declaratory action of constitutionality,

${ }^{1}$ Advogada, aluna do Programa de Mestrado em Direito, área de concentração Teoria e História do Direito, da Universidade Federal de Santa Catarina (UFSC). 
allegation of disobedience of fundamental precept from the Constitutionitself. After this brief history, the present article proposes to study the role of the Federal Supreme Court, in order to analyze if its function correlates with the one proposed by Hans Kelsen. For this, the present research was based on the inductive method, bibliographical research and doctrinal and legislative analysis.

Keywords:Constitutional Court. Constitutionality Control. Supreme Federal Court.

\section{INTRODUÇÃO}

No Estado Democrático de Direito, a Constituição assume o papel fundamental de limitar o poder político, cuja ideia de separação dos poderes é vista como princípio estrutural do Estado Constitucional. Nesse contexto, destaca-se o Judiciário, encarregado pela própria Constituição de promover a justiça e defender os direitos nela inseridos, assim como o próprio preâmbulo da Carta de 1988 traz.

A força normativa da Constituição confere validade ao Estado Democrático de Direito e a toda estrutura estatal, impondo a observância dos direitos e deveres nela previstos a todos os cidadãos e aos poderes do Estado. Nesse aspecto, faz-se primordial a análise das principais teorias do filósofo austríaco Hans Kelsen, dentre estas a teoria do positivismo normativoneokantiano e da jurisdição constitucional, as quais são indispensáveis para a compreensão da formação da jurisdição constitucional no século XX, bem como para a noção de supremacia da Constituição.

A partir da compreensão da teoria de Hans Kelsen e de seus impactos nos regimes democráticos da segunda metade do século XX, bem como das noções de estrutura da jurisdição constitucional e do papel exercido pelo Supremo Tribunal Federal no cenário brasileiro, problematiza-se a natureza do STF como possível corte ou tribunal constitucional e se esta corresponde ao ideal proposto por Hans Kelsen.

Nesse viés, por meio da utilização do método indutivo e da pesquisa bibliográfica, propõe-se a estudar o positivismo normativo de Hans Kelsen, assim como sua teoria da jurisdição constitucional de modo a inseri-la no sistema brasileiro e a identificar possíveis semelhanças e diferenças na aplicabilidade do modelo de controle de constitucionalidade concentrado atribuído a um órgão especializado.

\section{A PROPOSTA KELSENIADA DE CRIAÇÃO DE UM TRIBUNAL CONSTITUCIONAL}


A Teoria Pura do Direito (em alemão DieReine Rechtslehre), publicada por Hans Kelsen em 1934, propõeo escalonamento da ordem jurídica, onde a Norma Fundamental (Grundnorm) encontra-se no topo, atuando como fundamento último de validade de todas as normas jurídicas, devendo as normas inferiores serem compatíveis com a norma superior.

A abordagem positivista-analítica de Hans Kelsen busca o fundamento de validade do sistema normativo dentro do próprio direito, mantendo a pureza da teoria. Os estudos do filósofo austríaco tiveram início em 1911, mas somente com o fim da primeira guerra mundial tomou força, desempenhando papel relevante na elaboração de muitas constituições, tal como a Constituição Austríaca ${ }^{2}$.

A problemática da teoria de Kelsen se preocupa com a própria validade objetiva do direito, isto é, ao fundamento de onde essas normas retiram sua validade. Historicamente, o elemento de validade das normas jurídicas esteve relacionado com fatores exteriores ao direito: na Idade Média, a validade do direito estava ligada a Deus; no Iluminismo relacionava-se com a ideia de Direito Natural; de acordo com a Escola da Exegese a validade apontava para a vontade do legislador; na Escola Histórica do Direito era indicada pelo Espírito do Povo; e por fim, na Jurisprudência de Interesses estava relacionada com a finalidade do direito de reconhecer os interesses que contribuem para a promoção da vida plena (SIMIONI, 2014, p. 181).

Por conseguinte, se o objetivo de Kelsen era difundir uma teoria pura do direito, o fundamento de validade não poderia residir em um elemento exterior ao próprio direito, ou seja, era preciso encontrar o fundamento de validade das normas jurídicas dentro do direito. A solução apontada por Kelsen se deu mediante a associação da validade das normas jurídicas inferiores com normas jurídicas hierarquicamente superiores.

Da ideia de uma ordem jurídica escalonada, materialmente falando, no cenário brasileiro o topo estaria ocupado pela Constituição da República Federativa do Brasil de 1988 (CRFB/88), elemento de validade de todas as normas, de modo que se pressupõe que sendo a constituição válida, as demais leis criadas em conformidade com ela também o são.

A hierarquia das normas jurídicas introduzida por Hans Kelsen foi responsável pela introdução no Direito Positivo da ideia de controle concentrado da constitucionalidade das leis e atos normativos a cargo de um órgão especializado como garantia da supremacia constitucional ${ }^{3}$.

\footnotetext{
${ }^{2}$ Hans Kelsen em sua obra "Jurisdição Constitucional” explica a estrutura da jurisdição constitucional adotada pela Constituição Alemã de 1919 e pela Constituição Austríaca de 1920, cuja colaboração kelseniana na redação fez com que se criasse a Corte Constitucional, órgão responsável pelo controle concentrado da constitucionalidade dos atos do legislativo e do executivo.

${ }^{3}$ Nesse aspecto o presente artigo propõe-se a analisar tão somente o modelo de Hans Kelsen, deixando de abordar as propostas de Carl Schmitt, Benjamin Constant e outros autores.
} 
Tal supremacia atribuída à Constituição da República Federativa do Brasilde 1988 (CRFB/88) a eleva à condição de elemento de validade de todas as normas, sendo a base do Estado Democrático de Direito, motivo pelo qual todas as normas jurídicas inferiores devem estar compatíveis, formal e materialmente, com a Constituição. A superioridade da Constituição implica, nesse viés, a revogação de todas as normas que estejam em dissonância com a Carta de 1988.

Desse modo, o controle de constitucionalidade é uma das formas democráticas de garantir a aplicação das disposições constitucionais conforme a interpretação que foi dada pelo Poder Constituinte, sendo inadmissível qualquer lei em desconformidade com esta interpretação (BONAVIDES, 2010).

Em virtude de a Constituição estar no ápice da estrutura jurídica de um Estado, ela deve ser respeitada "como fundamento de validade de todo ordenamento jurídico que dela decorre obrigatoriamente, sem exceção possível, sob pena de inconstitucionalidade” (WEEKS, 2003, p. 34). Por esse motivo, a superioridade hierárquica impõe que as normas abaixo da Constituição estejam verticalmente compatíveis, caso contrário, essa norma deverá ser retirada do ordenamento jurídico.

Nesse sentido, Weeks (2003, p. 37) destaca:

A pirâmide de Kelsen foi definitivamente adotada no sistema rígido-insculpida pelos Constituintes da República vigente, no seu artigo 59, que dispõe sobre o processo legislativo. Nessa estrutura a Lei Magna ocupa posição de superioridade em relação às demais normas, no vértice do sistema jurídico conferindo validade às disposições em harmônio com seus dispositivos. É nesse contexto que se avalia a legitimidade dos atos provenientes dos entes estatais e a legitimidade dos poderes do Estado, encarcerados incondicionalmente no contexto da rigidez e supremacia da Carta da República Federativa.

O controle de constitucionalidade das leis no sistema das constituições rígidas segue o escalonamento da ordem jurídica de Kelsen, numa estrutura piramidal, encontrando seu fundamento de validade na Constituição: "a inconstitucionalidade seria então, a inadequação entre uma norma inferior e a Carta Magna, perfazendo-se numa contrariedade normativa" (WEEKS, 2003, p. 47). Por essa razão, as normas inferiores devem estar em perfeita sintonia, caso contrário, a norma tida como inválida e incompatível será expurgada do sistema normativo.

Para realizar o controle de constitucionalidade das normas, Hans Kelsen, na obraJurisdição Constitucional, propôs a criação de um órgão encarregado de exercer a jurisdição constitucional, o qual deveria ser independente de qualquer outra autoridade estatal e atuar como aplicador do Direito, diferenciando-se da atividade de criação legislativa. Esse órgão deveria 
ainda, estar subordinado à Constituição e encarregado de zelar pelo cumprimento das normas constitucionais (KELSEN, 2003, p. 150-151).

Nas palavras do jurista austríaco:

O órgão legislativo se considera na realidade um livre criador do direito, e não um órgão de aplicação do direito, vinculado pela Constituição, quando teoricamente ele o é sim, embora numa medida relativamente restrita. Portanto não é com o próprio Parlamento que podemos contar para efetuar sua subordinação à Constituição. É um órgão diferente dele, independente dele e, por conseguinte, também de qualquer outra autoridade estatal, que deve ser encarregado da anulação de seus atos inconstitucionais - isto é, uma jurisdição ou um tribunal constitucional (KELSEN, 2003, p.150).

Em síntese, Kelsen (2003) defendeu a criação de uma Corte Constitucional sob o fundamento de não poder confiar a invalidação de uma lei inconstitucional ao mesmo órgão que a elaborou, haja vista que a proteção da Constituição se dá por meio da jurisdição constitucional e, por isso, é imprescindível que exista um órgão independente dos demais poderes que garanta a supremacia da Constituição.

Nesse viés, o Tribunal Constitucional atuaria como um legislador negativo, exercendo a jurisdição constitucional do modo como absolutamente determinada pela Constituição. Isto é, na anulação de uma lei por parte de um Tribunal Constitucional se produz aplicação das normas da Constituição, uma vez que a livre criação legislativa está quase que completamente ausente.

\section{O CONTROLE DE CONSTITUCIONALIDADE NO BRASIL}

No Brasil, o controle de constitucionalidade exercido pelo Judiciário não esteve inserido na Constituição Política do Império o Brasil de 1824, outorgada por D. Pedro I. Por esse motivo, não há o que se falar em uma constituição rígida, e consequentemente numa jurisdição constitucional, eis que a ideia de supremacia da Constituição correlaciona-se à existência de uma constituição rígida em razão de que, nas constituições flexíveis, inexiste diferença formal entre norma constitucional e norma infraconstitucional.

Em 1890, sob influência do judicial review norte-americano, a Constituição Provisória de 22 de junho de 1890 (Decreto $\mathrm{n}^{\mathrm{o}}$ 510) previu no art. 58, inciso III, alínea $b$, a possibilidade de o Supremo Tribunal Federal, como órgão do Poder Judiciário da União, rever os processos findos, quando se questionar sobre a validade, ou a aplicabilidade de tratados e leis federais, e a decisão do tribunal do Estado for contra ela; e ainda quando se contestar a validade de leis ou atos dos 
governos dos Estados em face da Constituição, ou das leis federais e a decisão do tribunal do Estado considerar válidos os atos, ou leis impugnados.

Posteriormente, o Decreto $\mathrm{n}^{\mathrm{o}} 848$, de 11 de outubro de 1890, expedido durante o Governo Provisório de Deodoro da Fonseca, dispôs que a Justiça Federal seria exercida pelo Supremo Tribunal Federal e pelos juízes inferiores, e que aos magistrados caberia a guarda e aplicação da Constituição e das leis nacionais $\left(\operatorname{art} .1^{\circ}\right.$ e $\left.\operatorname{art} .3^{\circ}\right)$.

Ao proceder à leitura da última parte do artigo $3^{\circ}$, o qual prevê que "Na guarda e applicação da Constituição e das leis nacionaes a magistratura federal só intervirá em especie e por provocação de parte", o trecho "só intervirá em espécie e por provocação da parte"faz referência ao controle de constitucionalidade difuso presenteno direito norte-americano.

A Constituição de 1891 ampliou o controle incidental previsto no Decreto $\mathrm{n}^{\circ} 848$, om 1891, permitindo tanto a Justiça Federal quanto a Justiça Estadual declararem incidentalmente a inconstitucionalidade das leis. Elaborada por Rui Barbosa, a Carta de 1891 foi responsável por consagrar o controle de constitucionalidade fruto dojudicial reviewdo direito norte-americano, mencionado pela primeira vez no julgamento de Marbury v. Madison ${ }^{4} \mathrm{em} 1803$ no qual se atribui à Suprema Corte dos Estados Unidos a competência de interpretar as normas jurídicas à luz da constituição a partir de um caso concreto (CAMPOS, 2015).

Por outro lado, a Constituição de 1934 deixou de prever expressamente que caberia ao Supremo e aos juízes inferiores a guarda e aplicação da Constituição, tendo apenas mencionado no artigo 10, inciso I, que compete concorrentemente à União e aos Estados velar na guarda da Constituição e das leis.

Outra mudança foi em relação a nomenclatura, passando o STF a se chamar Corte Suprema, conforme o artigo $9^{\circ}$ da Carta de 1934. Contudo, houve apenas a mudança terminológica do órgão, haja vista terem sido mantidas as disposições da Constituição de 1891 no que concerne ao controle incidental de inconstitucionalidade das leis.

Uma inovação a ser mencionada refere-se a possibilidade de declaração de inconstitucionalidade pronunciada pelo voto da maioria absoluta dos membros dos tribunais; no art. 91, inciso IV e art. 96, a respeito da competência do Senado Federal, após comunicação do Procurador Geral da República, para suspender a execução de lei ou ato declarado inconstitucional pelo Judiciário; e ainda, a criação da ação direta de inconstitucionalidade

4A respeito desse julgamento histórico, Campos (2015) comenta: "Em 1803, a Suprema Corte julgou o caso Marburyv.Madison, e, pela primeira vez, realizou aquilo que marcaria para sempre o seu lugar no sistema político estadunidense e na história do constitucionalismo mundial - ela julgou inconstitucional um alei federal e declarou sua nulidade. Para chegar a tanto, a Suprema Corte afirmou o extraordinário poder da judicial reviewem relação às leis federais sem que decorresse claramente do Texto Constitucional de 1787". 
interventiva, cuja arguição competia ao Procurador Geral da República, estando sujeita a julgamento no Supremo Tribunal Federal Iart. 12, V, $\S 2^{\circ}$ ).

A nomenclatura Supremo Tribunal Federal foi retomada na Constituição de 1937 e alterou o número de juízes, passando para 11 (onze), podendo, contudo, este número ser elevado para 16 (dezesseis) nos termos do artigo 97.

De certo modo, percebe-se um enfraquecimento do Poder Judiciário quando se procede à leitura do art. 96, parágrafo único, in verbis:

\begin{abstract}
Parágrafo único: No caso de ser declarada a inconstitucionalidade de uma lei que, a juízo do Presidente da República, seja necessária ao bem-estar do povo, à promoção ou defesa de interesse nacional de alta monta, poderá o Presidente da República submetê-la novamente ao exame do Parlamento: se este a confirmar por dois terços de votos em cada uma das Câmaras, ficará sem efeito a decisão do Tribunal.
\end{abstract}

No que tange à ação direta de representação interventiva e a possibilidade de o Senado Federal suspender a execução de lei ou ato normativo declarado inconstitucional, o texto constitucional de 1937 restou omisso nesse sentido.

A Carta de 1946 retomou os institutos previstos nas Constituições de 1891 e de 1934relativos ao controle de constitucionalidade (difuso-incidental) e à representação interventiva, tendo reiterado a competência do STF de julgar em recurso extraordinário decisões proferidas pelas instâncias inferiores que contrariassem preceito constitucional, sua validade ou que apresentasse interpretação contrária àquela do STF ou de outro tribunal (art. 101). O Poder Judiciário retomou suas funções principalmente pela revogação da possibilidade de o Poder Executivo tornar sem efeito a decisão de inconstitucionalidade proferida pelo Tribunal nos termos previsto no parágrafo único do art. 96 da Carta de 1937.

A inovação constitucional foi trazida pela Emenda Constitucional $n^{\circ} 16$ de 26 de novembro de 1965, a qual introduziu no Brasil o modelo de controle abstrato de constitucionalidade, inspirado no modelo europeu proposto por Kelsen ao dispor acerca da representação genérica de inconstitucionalidade. O art. 101, inciso $\mathrm{I}$, alínea $k$ atribuiu ao Supremo Tribunal Federal a competência de processar e julgar originariamente a representação contra inconstitucionalidade de lei ou ato de natureza normativa, federal ou estadual, encaminhada pelo Procurador-Geral da República.Nesse contexto, cita-se Souza Neto e Sarmento (2015): 


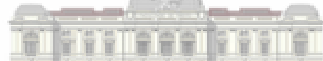

REVISTA ACADEIVICA

Faculdade de Direito do Recife

Vol.92 N.01 - Anno CXXIX

A partir da Emenda Constitucional 16/1965, o modelo tornou-se mais complexo, com a instituição do controle abstrato e concentrado de constitucionalidade, inspirado na matriz kelseniana, que passou a conviver lado a lado com o controle concreto e difuso, num sistema misto. O controle abstrato, todavia, não desempenhava papel relevante no sistema até a Constituição de 1988, porque só podia ser deflagrado por iniciativa do Procurador-Geral da República, que, àquela época, era agente político livremente nomeado pelo Presidente da República e a ele politicamente subordinado (p.77).

A mudança significativa que interessa para o âmbito de estudo do presente trabalho, adveio com a Emenda Constitucional de 1969, que elencou dentre as funções do Supremo, o controle de constitucionalidade nos termos do art.114, inciso III:

Art. 114 - Compete ao Supremo Tribunal Federal: III - julgar, mediante recurso extraordinário, as causas decididas, em única ou última instância, por outros Tribunais, quando a decisão recorrida: a) contrariar dispositivo desta Constituição ou negar vigência a tratado ou lei federal; b) declarar a inconstitucionalidade de tratado ou lei federal; c) julgar válida lei ou ato do Governo local, contestado em face da Constituição ou de lei federal; d) dar à lei federal interpretação divergente da que the haja dado outro Tribunal ou o próprio Supremo Tribunal Federal.

Como se pode observar, a Constituição de 1967 manteve os mesmos institutos previstos na carta anterior, porém, apesar de ter previsto o controle de constitucionalidade no rol de competências do Supremo, em momento algum mencionou que cabia a este a guarda da ordem constitucional. Foi somente na Constituição-cidadã é que o caput do art. 102 trouxe menção expressa à função de "guardião da Constituição" atribuída ao STF.

Nesse contexto, Barroso (2015, p. 6) destaca que antes da promulgação da CRFB/88, a ausência de seriedade em relação aos direitos fundamentais era tamanha que a população desacreditava o texto constitucional:

Com a promulgação da Constituição de 1988, teve início a luta teórica e judicial pela conquista de efetividade pelas normas constitucionais. Os primeiros anos de vigência da Constituição de 1988 envolveram o esforço da teoria constitucional para que o Judiciário assumisse o seu papel e desse concretização efetiva aos princípios, regrar e direitos inscritos na Constituição. Pode parecer óbvio hoje, mas o Judiciário, mesmo o Supremo Tribunal Federal, relutava em aceitar esse papel.

Por esse ângulo, o autor destaca que somente a partir dos anos 2000 o STF assumiu verdadeiramente a posição de intérprete da Constituição, sendo tal período caracterizado pelo rompimento com o positivismo normativo e início das decisões judiciais como um ato de escolha política. 
Como bem lembra Ferreira (2016), as ações de controle abstrato dotam de natureza objetiva, não tem partes, isto é, não há polos opostos discutindo direitos subjetivos, e são independentes da existência de uma lide. O que há, é a defesa objetiva da supremacia da Constituição e do interesse coletivo.

Nesse viés, de acordo com o previsto no art. 102, inciso I, alínea “a”, e o art. 103 da CRFB/88, o controle concentrado de leis e atos normativos federais e estaduais de competência do Supremo Tribunal Federal pode se dar por meio de Ação Direta de Inconstitucionalidade (ADI), seja genérica, por omissão ou interventiva; pela Ação Declaratória de Constitucionalidade (ADC) ou pela Arguição de Descumprimento de Preceito Fundamental (ADPF).

A Arguição de Descumprimento de Preceito Fundamental (ADPF) ${ }^{5}$ foi introduzida na Constituição pela Emenda Constitucional n 3, de 17 de março de 1993 como norma de eficácia limitada dependente de edição de lei. Para tanto, o Congresso Nacional editou a Lei n. 9.882, de 3/12/1999, regulamentando a ADPF, tendo elencado em seu art. $2^{\circ}$ os mesmos legitimados para propor a ADI e dispondo que a ação tem por objeto evitar ou reparar lesão a preceito fundamental, resultante de ato do Poder Público (art. $1^{\circ}$ ).

\section{A NATUREZA DO SUPREMO TRIBUNAL FEDERAL SOB A ÓTICA DA TEORIA KELSENIANA}

A Constituição da República Federativa do Brasil de 1988 atribuiu ao Supremo Tribunal Federal a função de guardião dos preceitos fundamentais, estando incluídos os direitos fundamentais e bases da estrutura estatal, sendo tal previsão uma consequência dos estudos de Hans Kelsen, o qual colocou, no campo prático, a Lei Fundamental (Grundgesetz) ou Constituição de um país no topo de seu ordenamento jurídico ${ }^{6}$.

Weeks (2003, p.34) explica que Hans Kelsen, ao idealizar a estrutura piramidal situando a Constituição no topo da pirâmide imaginária, fez com que ela conferisse validade a todas as leis e aos atos que são hierarquicamente subordinados à Constituição e por isso devem ser necessariamente compatíveis com ela.

\footnotetext{
${ }^{5}$ Mendes (2012, p.66) não inclui a ADPF no rol de ações típicas de controle abstrato de constitucionalidade por entender que "[...] a arguição de descumprimento tem como parâmetro de controle os preceitos fundamentais identificados ou identificáveis na Constituição. Trata-se de elemento menos preciso do que o parâmetro de controle do incidente de inconstitucionalidade (toda a Constituição)"

${ }^{6}$ Nesse ponto o presente artigo não se refere a norma fundamental hipotética pensada por Hans Kelsen como elemento de validade do ordenamento jurídico, mas tão somente no campo prático qual seria a norma superior que confere validade às demais.
} 
Por esse motivo, dada a supremacia da Constituição, Barroso (2015) explica que a função principal exercida pelo Supremo Tribunal Federal é a jurisdição constitucional, isto é, a interpretação e aplicação dos preceitos constitucionais mediante o julgamento das ações de controle de constitucionalidade abstrato e dos processos subjetivos. Nas palavras do autor:

Ao prestar jurisdição constitucional nos diferentes cenários pertinentes, cabe à Corte: (i) aplicar diretamente a Constituição a situações nela contempladas, como faz, por exemplo, ao assegurar ao acusado em ação penal o direito a nãoautoincriminação; (ii) declarar inconstitucionalidade de leis ou atos normativos, como fez no tocante à resolução do TSE que redistribuía o número de cadeiras na Câmara dos Deputados; ou (iii) sanar lacunas dos sistema jurídico ou omissões inconstitucionais dos Poderes, como fez ao regulamentar a greve no serviço público (BARROSO, 2015, p.18).

A CRFB/88, ao adotar parcialmente o modelo kelseniano, atribuiu ao Supremo a função de "legislador negativo", posto que não goza da competência de criação legislativa, mas dota do poder de retirar do ordenamento jurídico, revogando total ou parcialmente, qualquer lei ou ato normativo que atente contra os preceitos constitucionais ou contra sua correta interpretação.

Assim, ao zelar pela correta interpretação e aplicação da Constituição no âmbito de sua atuação, o Supremo Tribunal Federal exerce dupla função: a de um Tribunal Constitucional processando e julgando as ações de controle de constitucionalidade abstrato, bem como, a de Corte Suprema, pois julga em última instância os recursos provenientes de instâncias inferiores.

Todavia, não se mostra apropriado igualar a natureza do Supremo Tribunal Federal com a de um Tribunal Constitucional como, por exemplo, o Bundesverfassungsgericht(Tribunal Constitucional Federal) na Alemanha, uma vez que "o STF possui, além das competências clássicas caracterizadoras da jurisdição constitucional, diversas outras competências comuns, que acabam distanciando-o do modelo dos Tribunais Constitucionais europeus" (MORAES, 2000, p.219).

Ademais, no que tange a composição do STF, de acordo com o art. 101 da CRFB/88, é de 11 (onze) ministros vitalícios, escolhidos dentre cidadãos com mais de 35 (trinta e cinco) e menos de 65 (sessenta e cinco) anos de idade, de notável saber jurídico e reputação ilibada. Os ministros são nomeados pelo Presidente da República, depois de aprovada a escolha pela maioria absoluta do Senado Federal.

Como se observa, no que se refere a quantidade membros, sua estrutura não destoa daquilo proposto por Kelsen, uma vez que "o número de seus membros não deverá ser elevado, pois é sobre questões de direito que ela é chamada a se pronunciar, e ela deve cumprir uma missão puramente jurídica de interpretação da constituição" (KELSEN, 2003, p.153). No 
entanto, no que tange ao modo de escolha dos seus membros, tomando por base os ensinamentos de Kelsen, percebe-se que a escolha dos ministros do STF não condiz exatamente com os critérios sugeridos pelo jurista austríaco:

Entre os modos de recrutamento particularmente típicos, não poderíamos preconizar sem reservas nem a simples eleição pelo Parlamento, nem a nomeação exclusiva pelo chefe de estado ou pelo governo. Talvez fosse possível combinar ambas, por exemplo com o Parlamento elegendo juízes apresentados pelo governo, que deveria designar vários candidatos para cada uma das vagas a serem preenchidas, ou vice-versa. É da mais alta importância conceder, na composição da jurisdição constitucional, um lugar adequado aos juristas de carreira. Por exemplo, poder-se-ia conseguir isso atribuindo às Faculdades de Direito ou a uma comissão comum de todas as faculdades de Direito do país, um direito de apresentação para pelo menos uma parte das vagas, ou também atribuindo ao próprio tribunal o direito de fazer uma apresentação para cada vaga que surja ou de preenche-las por eleição, isto é, por cooptação" (KELSEN, 2003, p. 154).

Desse modo, referir-se ao STF como Tribunal Constitucional ou Corte Constitucional, não parece adequado, principalmente pelo fato de sua competência não residir exclusivamente na guarda da Constituição por meio do julgamento das ações de controle de constitucionalidade abstrato, mas também no julgamento dos Recursos Extraordinários, de acordo com o disposto no art. 102, inciso III, da CRFB/88.

Da leitura dos arts. 102 e 103 da CRFB/88 identifica-se duas funções do Supremo: a originária e a recursal. No exercício de sua competência originária, a função precípua que desempenha é a de Corte Constitucional, cuja finalidade é realizar o controle concentrado de constitucionalidade. Ao prever essa função, "a Constituição da República Federativa do Brasil, portanto, propôs ao STF o modelo de justiça constitucional europeu, que se fundamenta essencialmente e em regra na noção de um Tribunal Constitucional, com competência específica para conhecer os litígios constitucionais" (MORAES, 2000, p. 220).

O STF, assim como as cortes constitucionais, exerce o controle de constitucionalidade das leis e atos normativos emanados pelo Poder Legislativo e pelo Executivo, podendo, então, invalidar os atos emanados pelo Congresso Nacional, cuja composição é formada de representantes do povo eleitos por sufrágio universal, e também do Presidente da República, eleito pela soberania popular.

Referida postura já foi reiteradas vezes afirmada no Supremo ${ }^{7}$, tendo sido alegado que o controle concentrado de constitucionalidade transforma o Supremo Tribunal Federal em 
verdadeiro legislador negativo e que tão somente no controle de constitucionalidade é que o STF pode atuar como legislador negativo.

A CRFB/88 adotou, portanto, parcialmente ${ }^{8}$ o modelo kelseniano ao atribuir ao Supremo a função de "legislador negativo", posto que este não goza da competência de criação legislativa, mas do poder de retirar do ordenamento jurídico, revogando total ou parcialmente, qualquer lei ou ato normativo que atente contra os preceitos constitucionais ou contra sua correta interpretação.

O Supremo Tribunal Federal não é, por conseguinte, um tribunal constitucional em sua essência, pois além de apreciar as ações de controle de constitucionalidade abstrato, atua como última instância recursal. Nesse aspecto, vislumbra-se uma distorção na aplicação da teoria kelseniana de jurisdição constitucional, tendo em vista que Kelsen haveria prescrito a criação de uma corte especializada destinada a ser guardião da Constituição e não mero tribunal pertencente ao Poder Judiciário, tal como previu a CRFB/88 no seu art. 92, inciso I.

No intuito de transformar o STF em uma verdadeira Corte Constitucional nos moldes como previsto por Hans Kelsen, faz-se relevante mencionar que a Deputada Luiza Erundina de Sousa, do PSB/SP, propôs a PEC 275/2013 com o objetivo de criar a Corte Constitucional.

Atualmente, referida proposta de emenda constitucional pronta para Pauta na Comissão de Constituição e Justiça e de Cidadania (CCJC) e, se aprovada, altera a Seção II do Capítulo III do Título IV da CRFB/88 passando a denominar-se "Da Corte Constitucional" e modificando a redação dos artigos 101, 102, 104 e 105, de modo a altera a composição, a competência e a forma de nomeação dos Ministros do Superior Tribunal de Justiça e ainda, remodela a composição do Conselho Nacional de Justiça.

De acordo com a justificativa da PEC 275/2013 para a criação de uma Corte Constitucional:

A nova Corte seria, assim, composta de 15 (quinze) Ministros,nomeados pelo Presidente do Congresso Nacional, após aprovação de seus nomes pela maioria absoluta dos membros da Câmara dos Deputados e do Senado Federal, a partir de listas tríplices de candidatos oriundos da magistratura, do Ministério Público e da advocacia. Tais listas seriam elaboradas, respectivamente, pelo Conselho Nacional de Justiça, o Conselho Nacional do Ministério Público e o Conselho Federal da Ordem dos Advogados do Brasil(BRASIL, 2013, p.06).

\footnotetext{
${ }^{8}$ A CRFB/88 adotou de modo parcial o modelo de jurisdição constitucional proposto por Kelsen por ter atribuído ao Supremo Tribunal Federal competência originária e recursal, atuando não somente como Tribunal Constitucional mas também como última instância recursal e órgão do Poder Judiciário.
} 
Esse modo de escolha dos ministros que iriam compor a Corte dificultaria, de certo modo, as influências da política majoritária na escolha dos ministros, como ocorre atualmente em virtude da nomeação dos membros do STF pelo Presidente da República após a aprovação do Senado Federal, "além de estabelecer, já de início, uma seleção de candidatos segundo um presumível saber jurídico" (BRASIL, 2013, p.07).

A justificativa dada pela deputada é a de que a função precípua do STF, de guardar a Constituição, foi esquecida pelo acúmulo de processos sem relevância constitucional, causandolhe uma sobrecarga ao atuar como instância máxima do Poder Judiciário. Se aprovada, algumas de suas competências atuais são transferidas para o Superior Tribunal de Justiça. Por meio da redução de competências e ampliação do número de ministros, busca-se corrigir os principais problemas enfrentados pelo STF e se aproximar ainda mais do modelo alemão de "Corte Constitucional".

Vislumbra-se, por conseguinte, um acúmulo de funções no STF que o impede de atuar como verdadeiro guardião da Constituição. Essa sobrecarga de processos que são levados ao Supremo retarda sua capacidade em dar andamento às questões puramente constitucionais, haja vista sua dupla função: originária e recursal, as quais não permitem denomina-lo tribunal constitucional.

\section{CONSIDERAÇÕES FINAIS}

O Brasil possui um sistema misto de controle de constitucionalidade, adotando parte do modelo difuso norte-americano e parte do sistema alemão de controle concentrado, cuja adoçãodeu-se em 1965 por meio da Emenda Constitucional nº 16.

A incorporação do modelo germânico no ordenamento jurídico ainda é muito recente, principalmente pelo fato de o STF, apesar de já constar na carta de 1988 como guardião da Constituição, apenas a partir do ano 2000 parece ter assumido o papel de um suposto"Tribunal Constitucional".

Esse processo histórico e gradual influenciado pelo modelo kelseniano de organização da jurisdição constitucional, marcou-se pela existência de jurisdição encarregada de cumprir os preceitos constitucionais e realizar o controle de constitucionalidade das leis como expressão de sua força normativa, por intermédio de um Tribunal ou Corte Constitucional.

Desse modo, partindo-se do modelo escalonado de hierarquia das normas, a eficácia das normas constitucionais deve radiar aos demais ramos do Direito, posto que estas condicionam a interpretação das demais normas do ordenamento jurídico. Pode-se dizer, por esse raciocínio, que 
a Constituição limita a liberdade do legislador, sendo a validade das demais normas jurídicas submetidas à luz da Lei Maior.

O papel de guarda da Constituição foi atribuído ao STF pela CRFB/88, a quem cabe realizar o controle de constitucionalidade das normas que sejam incompatíveis formal e materialmente com a Carta de 1988 e, ainda, atuar como órgão recursal, decidindo em última instância, os Recursos Extraordinários.

Portanto, o STF não é uma corte constitucional na sua essência, uma vez que uma corte constitucional tal como proposto por Hans Kelsen não pode ser um tribunal híbrido, componente do Poder Judiciário que atue tanto como última instancia recursal e como guardião da constitucional simultaneamente.

\section{REFERÊNCIAS}

BARROSO, Luis Roberto. A razão sem voto: o Supremo Tribunal Federal e o governo da maioria. In: SARMENTO, Daniel. Jurisdição constitucional e política. 1.ed. Rio de Janeiro: Forense, 2015. p. 3-34.

BONAVIDES, Paulo. Curso de direito constitucional. 26.ed. Malheiros: São Paulo, 2010.

BRASIL. [Constituição (1824)]. Constituição Política do Império do Brasil. Rio de Janeiro, 1823. Disponível em: http://www.planalto.gov.br/ccivil_03/constituicao/constituicao24.htm. Acesso em: 11 ago.2018.

BRASIL.[Constituição (1891)]. Constituição da República dos Estados Unidos do Brasil. Rio de Janeiro, 1891. Disponível em:

http://www.planalto.gov.br/ccivil_03/constituicao/constituicao91.htm. Acesso em: 13 ago.2018.

BRASIL.[Constituição (1937)]. Constituição dos Estados Unidos do Brasil. Rio de Janeiro,1937. Disponível: http://www.planalto.gov.br/ccivil_03/constituicao/constituicao37.htm. Acesso em: 14 ago. 2018.

BRASIL. [Constituição (1946)]. Constituição dos Estados Unidos do Brasil. Rio de Janeiro, 1964. Disponível: http://www.planalto.gov.br/ccivil_03/constituicao/constituicao46.htm. Acesso em: 19 ago. 2018.

BRASIL.[Constituição (1967)]. Constituição da República Federativa do Brasil. Brasília: Senado, 1967. Disponível em:

http://www.planalto.gov.br/ccivil_03/constituicao/constituicao67.htm. Acesso em: 17 ago. 2018.

BRASIL. [Constituição (1988)]. Constituição da República Federativa do Brasil. Brasília: Senado, 1988. Disponível em:

http://www.planalto.gov.br/ccivil 03/constituicao/constituicaocompilado.htm. Acesso em: 12 jul.2018. 
BRASIL.Proposta de Emenda a Constituição 275/2013. Disponível em:

http://www.camara.gov.br/proposicoesWeb/fichadetramitacao?idProposicao=579931.Acesso em: 20 set.2018.

CAMPOS, Carlos Alexandre de Azevedo. Supremo Tribunal Federal, política e democracia, em Jurisdição Constitucional e Política. Rio de Janeiro: Forense, 2015.

CUNHA JUNIOR, Dirleyda.Controle de constitucionalidade: teoria e prática. 8.ed. Salvador: JusPodivm, 2016.

FERREIRA, Olavo Augusto Vianna Alves. Controle de constitucionalidade e seus efeitos. 3.ed. Salvador: JusPodivm, 2016.

KELSEN, Hans. Teoria pura do direito. Tradução de João Batista Machado. 6.ed. São Paulo: Martins Fontes, 1998.

KELSEN, Hans. Jurisdição Constitucional. 3.ed. São Paulo: Martins Fontes, 2003.

MENDES, Gilmar Ferreira; BRANCO, Paulo Gustavo Gonet. Curso de direito constitucional. 11.ed. São Paulo: Saraiva, 2016.

MORAES, Alexandre de. Jurisdição Constitucional e tribunais constitucionais: garantia suprema da Constituição. São Paulo: Atlas, 2000.

SIMIONI, Rafael Lazzarotto. Curso de hermenêutica jurídica contemporânea. 22.ed. Curitiba: Juruá, 2014.

SOUZA NETO, Cláudio Pereira de; SARMENTO, Daniel. Controle de constitucionalidade e democracia: algumas teorias e parâmetros de ativismo. In: SARMENTO, Daniel. Jurisdição Constitucional e Política. 1.ed. Rio de Janeiro: Forense, 2015. p. 73-114.

WEEKS, Lilian Rosemary. O controle da constitucionalidade da norma. Rio de Janeiro: Lumen Juris, 2003. 